\title{
Movimientos feministas y enfoques de género: integración del debate en las líneas curriculares para la formación de traductores en Chile'
}

\author{
Rosa Isabel Basaure-Cabero \\ rosita.basaure@usach.cl \\ Universidad de Santiago de Chile, Chile
}

\author{
Marcela Contreras-Torregrosa \\ marcela.contreras@usach.cl \\ Universidad de Santiago de Chile, Chile
}

\begin{abstract}
Resumen
La formación de traductores no puede quedar aislada del cambiante contexto internacional ni de las demandas sociales, puesto que estos profesionales se desempeñarán como agentes mediadores entre realidades lingüísticas, culturales e ideológicas diferentes. En este sentido, la problemática de género y los movimientos feministas debieran ser parte de las líneas curriculares y de investigación de la disciplina a nivel mundial. Sin embargo, esto no se refleja de manera activa en las universidades latinoamericanas. Esta investigación apunta a analizar esta problemática, particularmente desde el caso chileno, y establecer los lineamientos para incluirla en el currículo mediante una propuesta de cátedra específica, con metodologías pertinentes a nivel de pregrado y que además permitirá el desarrollo investigativo en la materia. Metodológicamente, la investigación se basa en el análisis de la situación del debate actual de género en los programas de Traducción en Chile desde el punto de vista curricular. A partir de estos resultados, se aborda el proceso de creación e implementación de una asignatura electiva que considera este aspecto como un eje formativo para el caso de la carrera de Licenciatura en Lingüística Aplicada a la Traducción de la Universidad de Santiago de Chile.
\end{abstract}

Palabras clave: traducción, formación de traductores, línea curricular, enfoque de género, Chile.

1 Este artículo se enmarca en el proyecto de investigación DICYT N 031751BC, "Sexismo lingüístico sintáctico, literatura infantil y traducción del discurso en los textos de las historias clásicas de Disney: Propuesta de análisis para traductores enfrentados a la paradoja de un fenómeno de la comunicación intercultural", de la Vicerrectoría de Investigación, Desarrollo e Innovación de la Universidad de Santiago de Chile. 


\title{
Feminist movements and gender perspective: Integrating the debate across the Translators' training curriculum
}

\begin{abstract}
Translators' training cannot be isolated from the constantly changing international context or from social demands, as these professionals will be mediating agents between different linguistic, cultural and ideological realities. In this regard, the issue of gender awareness and feminist movements should be part of the curriculum and research lines in this field worldwide. However, this has not been actively reflected on Latin American universities. This study seeks to analyze this issue, particularly from the Chilean perspective, and to establish guidelines to integrate it in the curriculum by proposing a specific course, with relevant undergraduate teaching methodologies that will also lead to research development in that field. Regarding the methodology, the study is based on the analysis of the current debate on gender awareness issues in Chilean Translation programs, from a curricular point of view. From these results, the process of developing and implementing an elective course that considers this topic as the central part of the training is addressed in the program of BA in Translation Studies of Universidad de Santiago de Chile.
\end{abstract}

Keywords: Translation studies, translators' training, curriculum, gender perspective, Chile.

\section{Mouvements féministes et approches sur l'identité de genre: Intégration du débat aux programmes d'enseignement pour la formation des traducteurs au Chili}

\section{Résumé}

La formation des traducteurs ne peut être séparée du contexte international changeant ni des demandes sociales car ces professionnels agiront en tant qu'agents de médiation dans différentes réalités linguistiques, culturelles et idéologiques. En ce sens, la problématique sur l'identité de genre et des mouvements féministes devrait être au programme d'enseignement et devrait faire partie de programmes de recherche à travers le monde. Cependant, cela ne se reflète pas activement dans les universités latino-américaines. Cette investigation vise à analyser cette problématique depuis un point de vue spécifiquement chilien et à établir les lignes de conduites à suivre, pour ensuite pouvoir l'inclure dans le programme d'enseignement grâce à la proposition de création d'un cours spécifique qui aura des méthodologies appropriées au niveau du premier cycle. De plus, cela permettra également le développement de recherches sur ce sujet. En ce qui concerne la méthodologie, l'investigation se base sur l'analyse de la situation actuelle par rapport au débat sur l'instauration de l'identité de genre dans les programmes d'enseignement de traduction au Chili. À partir des résultats obtenus, la discussion porte sur le processus de création et de mise en place d'un cours optionnel, dans lequel l'identité de genre est considérée comme un axe de formation en ce qui concerne le programme de $1^{\text {er }}$ cycle en linguistique appliquée à la traduction à l'Université de Santiago au Chili.

Mots-clés : Traduction, formation de traducteurs, programme d'enseignement, identité de genre, Chili. 


\section{Introducción}

Los seres humanos se relacionan a través de comunidades poseedoras de una identidad cultural propia que los une y los distingue de otros quienes no pertenecen a ese grupo o comunidad imaginada (Anderson, 1993). Dichas unidades culturales se han construido mediante el lenguaje que actúa como reflejo de su propia visión del mundo y juega un papel fundamental en la construcción de un imaginario colectivo, tanto en el modelamiento como en el desarrollo de los individuos, en el que los límites del lenguaje se transforman en los límites del pensamiento (Wittgenstein, 2012[1921]).

La traducción permite comprender y explicar las peculiaridades de los individuos de estas realidades diversas, en virtud de lo cual desempeña un papel decisivo como medio para el diálogo intercultural, entendido como un proceso horizontal de construcción, interacción y transformación entre culturas (Grimson, 2000), tanto en la difusión y adquisición de ideas como en el desarrollo de procesos de transformación social que pueden alcanzar una magnitud global. Además, este diálogo debe considerar las transformaciones que ocurren en el lenguaje en diferentes épocas históricas y diversas particularidades de las generaciones de hablantes (Paz, 1971).

En vista de lo anterior, cabe notar que los movimientos sociales en pro de la paz y el reconocimiento de los derechos civiles iniciados a fines de la década de 1960, particularmente en Estados Unidos y Europa Occidental, fueron motivados por factores variados, pero responden a cambios de patrones económicos, el rol internacional de Estados Unidos, el inicio de la Guerra Fría (Cantor, 1973) y el reconocimiento de los derechos civiles a partir de la etnicidad, la condición social y el género (Cohen, 1985; Melucci, 1989). La transformación social que dichos movimientos propiciaron reconfiguró nuevas propuestas de significado discursivo de esas identidades, no solo desde las perspectivas de las sociedades locales y sus conflictos identitarios particulares, sino en el sistema internacional, a partir de expresiones consideradas, como la redefinición de la identidad y la participación ciudadana como parte de un fenómeno global (Wallerstein, 2007). En ese contexto, en las distintas áreas del saber se abrió la reflexión sobre cómo desarrollar las disciplinas para ajustarse a las nuevas condiciones.

Los estudios de las lenguas y en particular la traducción han sido parte de este nuevo paradigma, debido a que los cambios sociales se reflejan en el traspaso de estas ideas de una lengua otra, por lo que las investigaciones en estas materias pueden considerarse ejes centrales en "la política de la trasmisión, en perpetuar o refutar los valores que sustentan la cultura literaria" (Simon, 1996, p. viii). La formación en traducción entonces tiene la responsabilidad de formar a los individuos que sean garantes del traspaso eficiente de dichas transformaciones sociales plasmadas en la lengua, lo que hace necesaria la permanente actualización de los objetivos, la didáctica y los contenidos de las mallas curriculares que preparan a estos profesionales para desarrollarse en un contexto sociocultural y discursivo cambiante.

En este contexto, parte de dicha reflexión respecto de la investigación, la enseñanza y la práctica de las distintas disciplinas ha sido la importancia del factor de género, entendido para esta investigación no como una mera distinción biológica sino como un factor construido a partir de visiones dinámicas (Butler, 1990) y holísticas (Ehrlich, 1997). De acuerdo a los postulados de estos autores, para este estudio el género se puede entender como un 
factor sociocultural, definido como el conjunto de prácticas sociales y culturales que incluyen elementos transnacionales a la hora de construir y representar visiones globales de identidad, pero también particularidades sexuales, históricas, culturales, sociales y de vinculación, que varían de una cultura a otra y de una generación a otra mediante procesos dinámicos.

En este sentido, el avance de los estudios de traducción respecto a cómo este factor se refleja en el lenguaje se inició en la década de 1970, en Canadá, específicamente en Quebec, donde existía un ambiente cultural e ideológico particular como resultado de la preocupación por el desarrollo ideológico de la traducción en relación con la valoración de lenguas que se encuentran subordinadas políticamente a una lengua dominante (Von Flotow, 2006). Esto permitió el surgimiento de estudios tendientes a analizar la relación entre traducción y la influencia de los estereotipos lingüísticos y sociales, la ideología y la política en un contexto en el que los traductores comprenden el texto de origen, traducen al texto meta creando significado y además viven y ejercen su labor en un contexto sociopolítico determinado (Federici, 2011).

Gracias a los esfuerzos de equipos de traducción canadienses y en especial de traductoras y académicas, como Sherry Simon y Luise von Flotow, comenzó la teorización y experimentación práctica de la traducción desde el punto de vista del género y del feminismo, tendientes a integrar este tema a los estudios como una línea del debate disciplinar, al analizar la relación entre género y traducción como medio de construcción cultural. Aquí la traducción tiene como objetivo la búsqueda de la descripción representativa de las experiencias femeninas mediante el lenguaje, particularmente a partir de cuatro elementos:
1) la visibilización de autoras y traductoras; 2) la revisión de contenidos que fueron traducidos con marcas de género; 3) la problemática de la traducción desde el enfoque del lenguaje no sexista y 4) la intervención social por medio de esta (Castro, 2008).

Los estudios en este ámbito posteriormente avanzaron hacia una etapa en la que se integraron la identidad queer y las teorías performativas de género (Butler, 1990), considerando tres puntos fundamentales (Von Flotow, 2011): 1) El equipo traductor tiene un amplio margen de libertad para plasmar el discurso en el texto meta, lo que tiene como resultado una gran influencia en la configuración del texto (Penas, 2015); 2) el texto meta se adapta a los paradigmas culturales de la lengua a la que se traduce; no obstante, puede trabajarse en conjunto desarrollando un texto de carácter flexible, lo que lo hace un acto performativo cultural (Von Flotow, 2011), y 3) la traducción tiene un espacio dinámico $\mathrm{y}$, por tanto, existe la necesidad de revisión constante (Penas, 2015).

Pero estos avances no solo tuvieron lugar en Canadá y Estados Unidos. Esta arista de la traducción también marcó presencia en el debate europeo gracias a los trabajos de José Santaemilia (2005) y Olga Castro (2008, 2013), entre otros, que desarrollaron líneas de análisis en los aspectos de la teoría, la práctica profesional y la enseñanza en esta materia.

No obstante, en América Latina, esta relación no se había considerado un área prioritaria hasta los movimientos sociales de los últimos años, que instalaron el género en el debate social y plantearon la necesidad de reflejar la discusión internacional en la traducción. Se comenzó a desarrollar una percepción regional que puede manifestarse en acciones como la apertura de grupos de trabajo investigativo en el área, publicaciones especializadas y mo- 
dificaciones curriculares que incluyan experiencias y prácticas pedagógicas relacionadas con esta materia.

Esta investigación se ha enfocado particularmente en la exploración del caso chileno como proyección de la situación regional de la traducción, considerando que las movilizaciones sociales de 2018 convirtieron el género en un eje de discusión social. Asimismo, los estudios en esta materia han comenzado a considerarse tanto dentro de la comunidad profesional como en las instituciones de educación que preparan a los futuros traductores, lo que proyecta el avance de este tema mediante la práctica profesional, la reflexión teórica y la incorporación de contenidos a través de propuestas curriculares que se explicarán en este trabajo.

El estudio busca, por una parte, mostrar de manera descriptiva la situación actual de los programas de traducción en Chile en esta temática, haciendo énfasis en las posibilidades de plantear este tema como un caso de análisis para el resto de los países de la región. Además, se presenta una propuesta curricular para el programa de Licenciatura en Lingüística Aplicada a la Traducción de la Universidad de Santiago de Chile, a partir del desarrollo de una asignatura electiva que considera este aspecto como un eje formativo para los futuros traductores que también permitirá el posterior desarrollo investigativo en la materia.

Este artículo se organizó en tres secciones: en la primera, se analizó la sociedad chilena a partir del enfoque de género, considerando su evolución histórica hasta las movilizaciones sociales de 2018. Este apartado descriptivo entrega el contexto necesario para comprender la situación de la educación superior para la traducción en Chile, para lo que se consultó fuentes documentales históricas, documentos oficiales de actores del Estado y la sociedad civil y fuentes documentales actualizadas de prensa nacional.

En la segunda sección, se analizó los programas de traducción a partir de la revisión de fuentes bibliográficas de formación para la traducción y fuentes académicas oficiales, tales como mallas curriculares y perfiles de egreso, disponibles en canales públicos de difusión oficiales. Además, se realizó la selección de una muestra representativa de programas de traducción vigentes en Chile, en los que se describen estrategias pedagógicas de inclusión de la temática de género, por lo que se revisaron documentos oficiales de sus programas, tales como descriptores de asignatura, informes de autoevaluación e informes de acreditación. Esta información se complementó con entrevistas de carácter semiestructurado con las autoridades académicas de las mismas universidades.

En la tercera sección de este trabajo se considera el análisis específico del programa de Licenciatura en Lingüística aplicada a la Traducción de la Universidad de Santiago de Chile y la propuesta de asignatura que surge a partir de las inquietudes de los mismos estudiantes de la carrera y del petitorio generado por las movilizaciones universitarias a las que este estudio hace referencia.

El trabajo concluye con una reflexión respecto de la responsabilidad de las instituciones de educación superior de educar a los futuros profesionales considerando un contexto global cambiante y se propone el factor de género como contenido relevante en el estudio, la práctica y la formación en traducción.

Este trabajo permitirá levantar un corpus inicial para contar con un marco preliminar y actualizado de la situación de los programas 
de traducción en Chile, que abra el camino para la flexibilización del currículo académico en este campo, lo que constituye una oportunidad para el desarrollo de nuevas líneas de formación, práctica e investigación de la traducción en América Latina, a partir de la experiencia actual chilena.

\section{Chile y la evolución hacia los movimientos feministas de 2018}

Para contextualizar, se puede señalar que, luego de la independencia de Chile en 1810, la presencia femenina aumentó y luego se fortaleció con la fundación de la primera Escuela para Señoritas en 1828 (De Ramón, 2003). Esto permitió el desarrollo de su participación en el ámbito social y gatilló los primeros movimientos feministas en el siglo XIX que se manifestaron respecto del ingreso de la mujer a los niveles superiores de educación y el acceso al trabajo remunerado (Morgan, 1993).

Sin embargo, a principios del siglo $\mathrm{xx}$, pese a la posibilidad de acceso a la educación formal y a la inclusión progresiva de la mujer en la sociedad chilena, las oportunidades laborales y de educación superior eran casi exclusivamente para la élite económica, mientras que el resto de la población femenina debía considerar trabajos con menor capacitación y, por tanto, con menores salarios. Por otra parte, la oposición religiosa católica hizo que solo recién en 1934 se aprobara el voto femenino para las elecciones municipales, y se alcanzó la paridad de participación recién en la elección presidencial de 1970 (Gaviola, Jiles, Lopresti \& Rojas, 1986).

Se crearon organizaciones como el Comité Nacional Pro-Derechos de la Mujer, en 1933; el Movimiento Pro-Emancipación de las Mujeres de Chile (мемсн), en 1935, y la Federación Chilena de Instituciones Femeninas
(FECHIF), en 1944. Estos organismos promovieron la organización y participación de las mujeres de diversos estratos sociales y niveles educacionales con la finalidad de cambiar su situación en Chile (Gaviola et al., 1986).

Pese a los avances, entre 1970 y 1989, la lucha por los derechos civiles desde la perspectiva de género quedó supeditada dada la situación política chilena. Las mujeres jugaron un papel relevante particularmente en la organización de comités de resistencia a la dictadura de la época (Observatorio de Género y Equidad, 2013) y en las movilizaciones sociales que apoyaban el plebiscito que finalmente terminaría con el gobierno autoritario de Pinochet en 1988 (De la Maza, 2005).

Con el retorno de la democracia en 1989, se generaron profundos cambios sociales que incluyeron la reforma del Estado y la incorporación activa a los organismos internacionales. Se planteó la necesidad de revisar la posición chilena frente a los temas de la agenda internacional, como la agenda de equidad de género, y se inició la transformación del marco regulatorio dejado por la dictadura para crear instituciones que permitieron lograr avances considerables en la posición de las mujeres dentro de la sociedad chilena.

La institución más importante en este ámbito fue el Servicio Nacional de la Mujer (SERNAM) en 1991, que lideró la promoción de políticas y programas públicos orientados a la equidad de género y a eliminar toda forma de discriminación, abriendo el camino mediante el sustento a la transformación del sistema público y el marco regulatorio chileno, por ejemplo, promoviendo leyes tales como la del divorcio en 2004 (Biblioteca Nacional del Congreso de Chile, 2004) y la ley de acceso a la educación preescolar (Gobierno de Chile, 2013). Para continuar apoyando el desarrollo de este 
ámbito de la política pública, el SERNAM fue reorganizado y declarado ministerio en 2016 (Ministerio de la Mujer y la Equidad de Género, 2018).

El avance en la situación de las mujeres y las representaciones sociales de género en Chile, junto con la proclamación de Michelle Bachelet como la primera presidenta en 2006 y su reelección en 2014, modificó de manera definitiva la visión respecto de la imagen de autoridad política y en especial de la mujer como individuo activo ejecutor de poder, el rol de la mujer dentro de la sociedad chilena y la representación de la agenda internacional de género vista desde la perspectiva chilena.

\subsection{La ola feminista de 2018}

La transformación del rol femenino y el cambio de paradigma a nivel internacional frente al género influyó en el desarrollo de manifestaciones respecto de la necesidad de equidad en la sociedad, lo que no solo incrementó las denuncias de violencia física y sicológica hacia las mujeres y las diversidades sexuales, sino que inició transformaciones respecto de los roles y estereotipos de género, la discriminación y la inequidad en todos los ámbitos de la sociedad. Las manifestaciones locales, definidas por los medios de comunicación como la nueva ola feminista chilena (Sepúlveda, 2018), no es un fenómeno aislado, sino que es un reflejo de la constante evolución social y cambio en las representaciones de género en Chile, el resto de América Latina y el mundo.

\subsection{Movilizaciones en la educación superior}

En Chile, este movimiento social se gestó inicialmente como reflejo del contexto internacional y de los movimientos Ni una menos (2015 en Argentina) y Me Too (2017 en EE.UU.). Sin embargo, luego de conocerse a través de los medios de comunicación de casos locales de violencia de género, tales como el feminicidio frustrado de Nabila Riffo en noviembre de 2016 (Vera, 2017), se generaron las primeras marchas en Santiago que exigían el fin de la violencia de género, además de denunciar la desigualdad laboral, criticar el modelo de educación sexista y visibilizar esta problemática en las instituciones educativas (Montes, 2018).

Las primeras movilizaciones que involucran instituciones educativas chilenas se produjeron en 2016 por casos de acoso sexual y laboral denunciados por estudiantes y funcionarios de la Universidad de Chile, lo que llevó a la primera toma fundada en demandas feministas, en octubre de 2017. En abril de 2018 se sumó a la movilización feminista la Universidad Austral de Chile (UACH), debido a la falta de proceso en casos de acoso y abuso entre estudiantes y las dificultades y lentitud de un caso de acoso sexual a una funcionaria por parte de un profesor del plantel. Las estudiantes exigían que las autoridades de la universidad mejoraran los protocolos y reglamentos en temáticas de género. $\mathrm{Al}$ mismo tiempo, instituciones de educación secundaria y de educación superior tanto públicas como privadas a lo largo de todo Chile fueron integrándose a las movilizaciones mediante paro de actividades o toma de instalaciones, tales como la Pontificia Universidad Católica de Chile, Universidad Técnico Federico Santa María, Universidad Diego Portales, Universidad de la Frontera, Universidad Católica de Valparaíso y Universidad de Santiago de Chile, entre otras (eldinamo.cl, 2018).

Dichas manifestaciones se acrecentaron tras conocerse denuncias de acoso y abuso sexual en la industria fílmica del país, así como las condiciones y brechas salariales entre hombres y mujeres en los medios de comunicación masivos, que hicieron visibles las mismas 
prácticas denunciadas por los movimientos feministas internacionales. Igualmente, se hicieron públicas denuncias por acoso en distintas universidades del país, las cuales fueron derivadas a los canales regulares de las instituciones para prevenir, investigar y sancionar faltas de funcionarios y académicos mediante procesos administrativos obsoletos en estas materias. La lentitud y la falta de sanciones efectivas a los acusados, así como la falta de reparación a las víctimas motivaron movilizaciones que sumaron 32 universidades e instituciones de educación superior y 9 instituciones de educación secundaria para julio de 2018 (cooperativa.cl, 2018).

Esta situación hizo visible la disconformidad social respecto de las relaciones de género en la educación. Se exigieron nuevos protocolos que resguardaran a estudiantes, funcionarios y académicos en casos de acoso, así como la suspensión de sus funciones y expulsión de las personas responsables de dichas prácticas. Los puntos centrales de las movilizaciones fueron:

a) Órganos y reglamentos: reflexión y prevención por medio del establecimiento de organismos y mecanismos de acción para la prevención, tratamiento y disminución de la violencia de género en las instituciones educativas.

b) Articulación triestamental: creación de directrices de equidad de género para estudiantes, académicos y funcionarios.

c) Financiamiento: revisión de las mallas curriculares para la incorporación de contenidos con equidad de género para el desarrollo de los contenidos pedagógicos y de los contenidos y bibliografía que considere la variable de género a partir de la inyección de recursos para el logro de este objetivo. d) Educación no sexista: creación de asignaturas transversales y de especialidad con contenidos sobre equidad de género. (Guerra, 2018)

En este sentido, las instituciones de educación chilenas se enfrentan hoy a la necesidad de dialogar y revisar el rol de la temática de género en la educación de los futuros profesionales y avanzar hacia la implementación de protocolos que consideren el contexto internacional y local cambiante. De este modo, la formación académica no puede quedar aislada de las demandas sociales ni de los factores que influyen en el flujo de conocimiento.

\section{Formación de traductores y género: el caso chileno}

Considerando este escenario y la experiencia internacional de la disciplina en esta materia, se hace necesario revisar la situación actual en América Latina, así como la incorporación del género a la investigación y la formación de los traductores para llegar a ser profesionales humanistas integrales que deben estar conscientes de las inquietudes y necesidades del contexto en el que desarrollan su labor.

\subsection{Competencia traductora}

Para analizar la importancia de la formación respecto de la temática de género, que como se ha señalado representa una de las problemáticas que recientemente se ha abierto a debate en la comunidad internacional, es necesario hacer referencia a la competencia traductora, entendida como un subconjunto de competencias o habilidades que el estudiante debe desarrollar y fortalecer en el transcurso de su proceso de aprendizaje y durante su experiencia profesional (PACTE, 2001).

Estas subcompetencias corresponden a la competencia comunicativa, que se refiere a la compren- 
sión en la lengua de partida y producción en la lengua de llegada; la competencia extralingüística, que se entiende como los conocimientos de la organización del mundo; la de transferencia, que tiene que ver con el proceso de elaboración del texto final, lo que implica un proceso de comprensión del contexto; la psicofisiológica, que consiste en la aplicación de los recursos cognitivos que posee el traductor; la competencia instrumental, que comprende las habilidades necesarias a nivel profesional; y, por último, la competencia estratégica, como aquella que toma en cuenta los procedimientos que se usan para resolver los problemas que conlleva la traducción (PACTE, 2018).

Por otra parte, Kelly (2002) precisó en su investigación el concepto de competencia traductora o macrocompetencia, definiéndola como "[...] el conjunto de capacidades, destrezas, conocimientos e incluso actitudes que reúnen los traductores profesionales y que intervienen en la traducción como actividad experta" ( $p$. 14). Establece así el espectro de habilidades que se deben tener para ejercer la traducción de manera eficiente y, al mismo tiempo, los elementos que la formación debe considerar a la hora de planificar el currículo.

Estas pueden desarrollarse mediante una enseñanza reforzada con estrategias metodológicas como la comprensión y la producción textual en ambas lenguas de trabajo para la competencia comunicativa; el uso de casos reales en los que los estudiantes deban tomar decisiones y planificar el trabajo individual y de equipo para la subcompetencia estratégica; ejercicios de traducción para reforzar la subcompetencia de transferencia, y la reflexión y aplicación de los recursos físicos y psicológicos del individuo frente al desarrollo del proceso de traducción para la subcompetencia psicofisiológica.

Otros modelos advierten la importancia de la formación de la subcompetencia cultural, que responde a los conocimientos que debe tener el profesional en esta área respecto del contexto sociocultural tanto del texto de origen como del texto meta y la subcompetencia temática, que considera los conocimientos sobre temas específicos. Esto plantea diferentes escenarios en los que el traductor toma un rol más activo en el espacio intercultural de la obra (Venuti, 1999), donde incluso se habla de negociación y traducción como la única manera posible de transformar el mundo y provocar algo políticamente nuevo (Bhabha, 2002). Por lo tanto, la formación debe considerar la responsabilidad de los traductores en el logro de la cooperación entre culturas respetando la fuente, el vínculo, la narración, el contexto y los receptores de dicho discurso (Pym, 1998).

Por otra parte, Canale (1995) también plantea la importancia de la relación con el contexto en la formación de traductores y establece la relevancia de la formación y desarrollo de capacidades verbales y no verbales para resolver los conflictos en la comunicación intercultural. En este mismo nivel, Bachman (1995) incorpora el factor de la resolución de los conflictos comunicativos o subcompetencia estratégica, considerando tanto las subcompetencias relacionadas con las funciones del lenguaje como con la adecuación de este lenguaje al contexto y por último, la subcompetencia interpersonal, que corresponde a la capacidad de relacionarse no solo con un equipo de trabajo, sino también con los clientes, sus necesidades y características particulares (Kelly, 2002).

En este mismo sentido, Kiraly incorpora tanto la competencia interpersonal, relacionada con el trabajo en equipo, el respeto y la empatía que se debe tener a la hora de relacionarse principalmente con el cliente y el usuario y la competencia cultural, que involucra conocer las tradiciones, los mitos, los valores, creencias y comportamientos de un país determinado 
(Kiraly, 2000). Todos estos elementos reflejan la importancia del contexto de las relaciones humanas a la hora del proceso de aprendizaje y luego al ejercer la traducción de manera profesional.

Frente a estos modelos de competencia traductora, se plantea la necesidad de desarrollar competencias de flexibilidad de aprendizaje, no solo al adaptarse a nuevos equipos de trabajo, clientes o términos de contrato, sino que también la necesidad de poder desempeñarse en distintas áreas temáticas tomando en cuenta las necesidades del mercado (Márquez, 2011). Así, este modelo se diferencia de los modelos de competencias traductoras tradicionales, puesto que plantea la necesidad de que los traductores actuales estén conscientes de los cambios que ocurren en el mercado laboral, pero también del contexto en el que se desarrolla la sociedad en la que se encuentran (Diéguez, Lazo y Quezada, 2014).

Se puede inferir entonces que es esencial el desarrollo de competencias lingüisticas y de transferencia como ejes articulatorios de los programas de Traducción. Sin embargo, es necesario también fortalecer las competencias asociadas a la resolución de problemas y la comprensión del contexto temático y sociocultural del discurso, especialmente considerando las temáticas que impactan a la sociedad desde el punto de vista de la diversidad, tal como ocurre con el factor de género.

Este enfoque integral permitirá lograr la participación efectiva de los traductores en el diálogo global como mediadores interculturales, asumiendo activamente el rol que la traducción tiene en el proceso comunicativo. Así, es responsabilidad de las instituciones de educación que forman a los traductores que tengan las herramientas necesarias para enfrentar este desafío que el mercado global les impone.

\subsection{Formación de traductores y género: la situación actual en Chile}

Hasta ahora, se ha señalado que la traducción, al ser un medio para explicar y comprender las diferencias y similitudes entre individuos de diversas culturas, no puede solo considerar lo lingüístico, sino que también lo social, cultural, político, filosófico y hermenéutico (Hurtado, 2001). Esto plantea la relación traducción y género como un vínculo a considerar al crear significado y establece la relevancia de la expresión de esta relación reflejada en el discurso mediante decisiones conscientes o inconscientes por parte de los traductores, en cuanto a que pueden convertirse "en una herramienta de activismo social" (Von Flotow, 2011, p. 4) que al mismo tiempo deben responder a un escenario extralingüístico permanentemente cambiante.

Considerando esta perspectiva, actualmente las movilizaciones sociales reivindican la importancia de este factor a nivel de la traducción y la necesidad de hacer eco de aquello revisando lo avanzado no solo desde la estructura del discurso, sino también desde la teoría, la práctica y la enseñanza de la disciplina.

En el caso de América Latina, pese a que la traducción se ha visto históricamente como una actividad enfocada en la mediación cultural, el énfasis se ha dado en la búsqueda y creación de identidades y el traspaso de conocimiento más que todo hacia la región desde los polos intelectuales de Estados Unidos y Europa (Gaspar, 2017). Esta situación hoy también se refleja en el creciente interés por el tema género abordado en los estudios de la traducción a nivel internacional, por lo que, debido a lo reciente de estos movimientos sociales y el impacto en las instituciones educativas, se hace necesario explorar la situación a este respecto. 
En este trabajo se analizará la situación en Chile como caso de estudio, respecto de la situación de la formación traductora y cómo las instituciones educativas han comenzado a hacerse cargo de la incorporación de la temática al contexto curricular. De este modo se podrá avanzar desde este espacio geográfico al desarrollo de estudios comparativos posteriores con otros países latinoamericanos y también a nivel interregional y global.

A continuación, se presenta la situación en Chile de los programas de traducción a partir de la revisión de la incorporación de la temática de género en los 27 programas de estudio en esta disciplina vigentes a la fecha. El universo de esta investigación está compuesto por un total de 4 programas conducentes al grado de técnico de nivel superior, con una duración promedio de 2 años; 3 programas que confieren el título profesional de traductor, con una duración promedio de 4 años, y los 15 programas restantes son licenciaturas. Además, se incluye en este análisis la oferta de 5 programas de postítulo y el único programa en Chile conducente al grado de magíster en la especialidad:

Tabla 1. Programas de estudio de traducción técnico profesional ofertados en Chile

\begin{tabular}{|c|c|c|}
\hline Nombre del programa & Institución & Zona geográfica donde se imparte \\
\hline $\begin{array}{l}\text { Interpretación de Enlace con } \\
\text { Mención Inglés-Castellano }\end{array}$ & $\begin{array}{l}\text { Instituto profesional EATRI (ex-Escuela } \\
\text { Americana de Traductores e Intérpretes) } \\
\text { (IP EATRI) }\end{array}$ & Región Metropolitana (Santiago) \\
\hline $\begin{array}{l}\text { Técnico en Traducción } \\
\text { Inglés-Español }\end{array}$ & $\begin{array}{l}\text { Instituto Profesional Chileno-Británico de } \\
\text { Cultura (IP CBC) }\end{array}$ & Región Metropolitana (Santiago) \\
\hline $\begin{array}{l}\text { Técnico de Nivel Superior en } \\
\text { Traducción Inglés-Español }\end{array}$ & $\begin{array}{l}\text { Instituto Profesional Valle Central } \\
\text { (IP VALLE CENTRAL) }\end{array}$ & No se oferta para año 2019 \\
\hline $\begin{array}{l}\text { Técnico de Nivel Superior en } \\
\text { Traductor Bilingüe }\end{array}$ & Universidad Arturo Prat (IP UNAP) & $\begin{array}{l}\text { Zona Norte: Arica, lquique, } \\
\text { Antofagasta, Calama } \\
\text { Región Metropolitana (Santiago) }\end{array}$ \\
\hline
\end{tabular}

Fuente: Elaboración propia a partir de Diéguez, Lazo y Quezada (2010) y datos publicados por las mismas instituciones en sus correspondientes sitios web actualizados al proceso de admisión 2019.

Tabla 2. Programas de estudio de traducción con título profesional ofertados en Chile

\begin{tabular}{lll}
\hline Nombre del programa & Institución & Zona geográfica donde se imparte \\
\hline $\begin{array}{l}\text { Traducción Inglés- } \\
\text { Español (diurno) }\end{array}$ & $\begin{array}{l}\text { Instituto Profesional Chileno-Norteamericano } \\
\text { (IP CHN) }\end{array}$ & No se ofertó para 2019* \\
\hline $\begin{array}{l}\text { Traducción Inglés- } \\
\text { Español (vespertino) }\end{array}$ & $\begin{array}{l}\text { Instituto Profesional Chileno - Norteamericano } \\
\text { (IP CHN) }\end{array}$ & No se ofertó para 2019 \\
$\begin{array}{lll}\text { Traductor Intérprete de } \\
\text { Enlace con Mención en }\end{array}$ & $\begin{array}{l}\text { Intituto profesional EATRI (Ex-Escuela } \\
\text { (IP EATRI) }\end{array}$ & Región Metropolitana (Santiago) \\
\hline Inglés & & \\
\hline
\end{tabular}

* El Instituto Chileno Norteamericano anunció en febrero 2017 su cierre programado. Mediante el Acuerdo Nº 31/2017, el Consejo Nacional de Educación de Chile informa al Ministerio de Educación que esto se hace efectivo a partir de enero de 2020, a fin de permitir que los estudiantes del instituto puedan finalizar sus procesos académicos pendientes (CNE, 2018).

Fuente: Elaboración propia a partir de Diéguez, Lazo y Quezada (2010) y datos publicados por las mismas instituciones en sus correspondientes sitios web actualizados al proceso de admisión 2019. 
Tabla 3. Programas de estudio de Traducción con grado de licenciatura ofertados en Chile

\begin{tabular}{|c|c|c|}
\hline Nombre del programa & Institución & Zona geográfica donde se imparte \\
\hline Traducción Inglés-Español & $\begin{array}{l}\text { Pontificia Universidad Católica de } \\
\text { Valparaíso (Pucv) }\end{array}$ & Zona central: Valparaíso \\
\hline Traducción Inglés-Español & $\begin{array}{l}\text { Universidad Chileno Británica de } \\
\text { Cultura (UCBC) }\end{array}$ & Oferta pendiente para $2019^{*}$ \\
\hline $\begin{array}{l}\text { Traducción o Interpretariado } \\
\text { Inglés-Español }\end{array}$ & $\begin{array}{l}\text { Universidad de Ciencias de la } \\
\text { Informática (UCINF) }\end{array}$ & Región Metropolitana (Santiago) \\
\hline Traducción Inglés - Español & Universidad Católica de Temuco (Uст) & Zona sur: Temuco \\
\hline $\begin{array}{l}\text { Traductor e Intérprete Inglés } \\
\text { Español }\end{array}$ & Universidad de Atacama (UDA) & Zona norte: Copiapó \\
\hline $\begin{array}{l}\text { Traducción Interpretación en } \\
\text { Idiomas Extranjeros }\end{array}$ & Universidad de Concepción (UDEC) & Zona sur: Concepción \\
\hline Traducción e Intérprete en Inglés & Universidad de las Américas (UDLA) & $\begin{array}{l}\text { Región Metropolitana (Santiago) } \\
\text { Zona Central: Viña del Mar }\end{array}$ \\
\hline $\begin{array}{l}\text { Traducción Inglés, Castellano } \\
\text { Inglés, Mención Francés }\end{array}$ & Universidad Arturo Prat (UNAP) & Zona norte: Iquique \\
\hline $\begin{array}{l}\text { Traducción e Interpretariado } \\
\text { Bilingüe }\end{array}$ & $\begin{array}{l}\text { Universidad de Artes, Ciencias y } \\
\text { comunicación (UNIACC) }\end{array}$ & Región Metropolitana (Santiago) \\
\hline $\begin{array}{l}\text { Traducción e Interpretación } \\
\text { Inglés-Español }\end{array}$ & Universidad de Playa Ancha (UPLA) & Zona central: Valparaíso \\
\hline Traducción Inglés - Español & Universidad de la Serena (USERENA) & Zona norte: La Serena \\
\hline Traductor(a) Inglés-Castellano & Universidad de Tarapacá (UTA) & Zona norte: Arica \\
\hline $\begin{array}{l}\text { Traducción Inglés Español } \\
\text { Mención Negocios Internacionales }\end{array}$ & $\begin{array}{l}\text { Universidad Tecnológica de Chile } \\
\text { (INACAP) }\end{array}$ & $\begin{array}{l}\text { Zona norte: La Serena } \\
\text { Zona central: Región Metropolitana } \\
\text { (3 sedes: Puente Alto, Santiago } \\
\text { Centro, Pérez Rosales) } \\
\text { Zona sur: Los Ángeles, Osorno }\end{array}$ \\
\hline $\begin{array}{l}\text { Licenciatura en Lingüística } \\
\text { Aplicada a la Traducción con } \\
\text { Mención en Inglés-Japonés o } \\
\text { Inglés-Portugués }\end{array}$ & $\begin{array}{l}\text { Universidad de Santiago de Chile } \\
\text { (USACH) }\end{array}$ & Región Metropolitana (Santiago) \\
\hline
\end{tabular}

* En noviembre de 2017, el Consejo Nacional de Educación evaluó el proyecto institucional y decidió no certificar la autonomía de la Universidad Chileno Británica de Cultura y solicitar al Ministerio de Educación la revocación del reconocimiento oficial y la cancelación de su personalidad jurídica. La universidad interpuso un recurso de reposición y mediante el Acuerdo N. ${ }^{\circ}$ 020/2018 el Consejo decidió rechazarlo y solicitar la cancelación de su personalidad jurídica. La universidad se encuentra en espera de la resolución final para abrir o no su proceso de admisión 2019 (CNE, 2018, p. 2).

Fuente: Elaboración propia a partir de Diéguez, Lazo y Quezada (2010) y datos publicados por las mismas instituciones en sus correspondientes sitios web actualizados al proceso de admisión 2019. 
Tabla 4. Oferta nacional de postítulo y postgrado en traducción en Chile

\begin{tabular}{|c|c|c|}
\hline Nombre del programa & Institución & Zona geográfica donde se imparte \\
\hline $\begin{array}{l}\text { Magíster en Traducción del } \\
\text { Inglés al Español }\end{array}$ & $\begin{array}{l}\text { Pontificia Universidad Católica de Chile } \\
\text { (PUC) }\end{array}$ & Región Metropolitana (Santiago) \\
\hline $\begin{array}{l}\text { Diplomado en Tecnologías } \\
\text { de la Traducción y Gestión } \\
\text { de Proyectos }\end{array}$ & $\begin{array}{l}\text { Pontificia Universidad Católica de Chile } \\
\text { (PuC) }\end{array}$ & Región Metropolitana (Santiago) \\
\hline $\begin{array}{l}\text { Diplomado en Traducción } \\
\text { Inversa }\end{array}$ & IP EATRI & Región Metropolitana (Santiago) \\
\hline $\begin{array}{l}\text { Diplomado en Traducción } \\
\text { Inversa }\end{array}$ & $\mathrm{IPCHN}$ & Región Metropolitana (Santiago) \\
\hline $\begin{array}{l}\text { Diplomado en Traducción } \\
\text { Especializada }\end{array}$ & PUCV & Sede Región Metropolitana (Santiago) \\
\hline Diplomado en Traducción & Universidad Católica del Norte (UCN) & Zona norte: Antofagasta \\
\hline
\end{tabular}

Fuente: Elaboración propia a partir de Diéguez, Lazo y Quezada (2010) y datos publicados por las mismas instituciones en sus correspondientes sitios web actualizados al proceso de admisión 2019.

Luego de revisar la información declarada por las mismas instituciones en canales de acceso público, se puede establecer que todos los programas consideran las dimensiones de la competencia traductora, con una fuerte promoción en la formación de competencia lingüistica en las lenguas de trabajo; la formación en competencias psicofisiológica y estratégica vinculadas a la autogestión, gestión de proyectos y trabajo en equipo y competencia instrumental en referencia a uso de tecnologías.

Se observa que la mayoría de los programas presentan referencias al contexto sociocultural y a la comunicación o mediación intercultural en algún grado, ya sea en una de sus asignaturas o en su perfil de egreso. Por ejemplo, la Universidad de Playa Ancha, evidencia en su malla curricular que existen asignaturas electivas que permiten la flexibilidad del programa y la incorporación de contextos temáticos diversos (Universidad de Playa Ancha, 2018), situación similar a la de la Universidad de Santiago de Chile (Universidad de Santiago de Chile, 2018).

También se evidencian perfiles de egreso que presentan conceptos como diversidad y res- peto, como en el caso de la Pontificia Universidad Católica de Valparaíso, que expresa que su egresado en esta área "actúa éticamente, iluminado por la propuesta cristiana, en contextos reales, con autonomía y respeto hacia los demás, buscando el bien común, la promoción de los derechos humanos y la realización de la persona humana, en un contexto de diversidad" (Pontificia Universidad Católica de Valparaíso, 2018), o el caso de la Universidad Chileno Británica de Cultura, que en su perfil de egreso establece que el profesional "respeta y valora la diversidad cultural en sus variadas expresiones." Asimismo, el perfil del traductor de la Universidad de Tarapacá plantea que el profesional "demuestra respeto y tolerancia por sus pares y el entorno social con quienes interactúa frecuentemente" (Universidad de Tarapacá, 2018) y, por su parte, la Universidad de Concepción expresa que "el plan de estudios cautela que el traductor/intérprete egresado sea creativo, flexible, reflexivo, capaz de adaptarse al cambio, con iniciativa, curiosidad intelectual, capacitado para resolver los problemas propios de su área de competencia, tolerante y respetuoso de la diversidad" (Universidad de Concepción, 2018). 
Es posible entonces observar que ninguna de las instituciones contempladas en el estudio aborda la temática de género expresamente en sus asignaturas ni la refleja directamente en su perfil de egreso.

\subsection{Incorporación de contenidos de género a los programas de estudio}

Mediante el análisis fue posible evidenciar la carencia de asignaturas que tratan específicamente la relación entre traducción y temáticas de género en los programas chilenos de especialidad. Es decir, no se presenta el factor de género ni desde la formación integral ni como contenido temático específico.

Sin embargo, las instituciones analizadas resuelven la incorporación de contenidos a las mallas curriculares mediante cuatro posibilidades pedagógicas que se presentan a continuación: 1) no considerar ninguna de las aristas de la temática de género en las mallas curriculares o en los contenidos; 2) incorporar contenidos temáticos específicos de dicho contexto a las asignaturas del programa de Traducción; 3) desarrollar actividades en paralelo a la malla curricular y 4) establecer asignaturas específicas en las mallas curriculares.

Estas alternativas pedagógicas abren la posibilidad de flexibilizar el currículo frente a la necesidad constante de integración de contenidos temáticos que fortalezcan las habilidades extralingüísticas y la formación integral de los futuros traductores. Estos no solo deberán desempeñarse considerando un escenario internacional cambiante, sino también los contextos socioculturales específicos que se establezcan a partir de los diversos movimientos sociales en los que los programas curriculares se encuentran inmersos, tal como el caso de los últimos procesos sociales analizados en este trabajo.
Así entonces, para profundizar la revisión de estas alternativas de integración al currículo, se seleccionó una muestra representativa de las entidades anteriormente mencionadas para llevar a cabo entrevistas semiestructuradas a sus autoridades académicas, a fin de obtener mayores datos sobre sobre la inclusión de contenidos o de desarrollo curricular.

En la muestra se incluyó la Escuela de Traductores e Intérpretes EATRI, por ser la institución más antigua en funcionamiento (1970), que abarca la educación superior técnico profesional (Instituto Profesional EATRI, 2018) y que no contiene ninguna referencia de contenidos pedagógicos, asignaturas o referencias del perfil del egreso a la temática de género; la Universidad Tecnológica de Chile INACAP, ya que pese a que la carrera de Traducción se ha cerrado en algunas de las sedes, de acuerdo con la información entregada en una comunicación personal con María Loreto Serrano, asesora del programa de Estudios de Traducción Inglés Español de esa universidad (28 de noviembre, 2018), todavía es la universidad con mayor cobertura geográfica con el programa de Traducción (Universidad Tecnológica de Chile InACAP, 2018); la Pontificia Universidad Católica de Chile, por ser el programa profesional de más larga data (1971) y donde actualmente se realiza el único programa de Magíster en Traducción en Chile (Pontificia Universidad Católica, 2018) y la Universidad de las Américas, por ser el programa que más recientemente ha considerado modificaciones en su malla curricular, al incluir el factor de mediación e interculturalidad (Universidad de las Américas, 2018).

E1 Instituto Profesional EATRI impartía la asignatura de Actualidad mundial, pero se eliminó de la malla en la última revisión curricular (2015-2016) y sus contenidos fueron incorporados a los textos de trabajo de las asignaturas 
de taller de traducción especializada enfocadas principalmente en la traducción económica y técnico - científica (Instituto Profesional EATRI, 2018). Asimismo, al plantear la posibilidad de una entrevista respecto del estudio, las autoridades señalaron abiertamente que "la institución no tienen en carpeta proyectos relacionados con el tema del género”, según la información entregada en una comunicación personal con Pía Torrealba, directora académica (12 de noviembre, 2018), por lo que se puede establecer que el enfoque de sus programas no solo no considera el factor de género como un eje de la formación académica, sino que tampoco fomenta actividades de extensión ni asignaturas electivas relacionadas con el eje contextual de la formación traductora. Con el tiempo, se evidencia la disminución de contenidos de este tipo en la malla curricular de sus programas.

En el caso de la Universidad Tecnológica de Chile (INACAP), es un programa que geográficamente responde a distintas realidades desde el punto de vista de las áreas económicas y productivas de Chile, por lo que ya presenta un desafío a la hora de planificar un programa de Traducción que va a desarrollarse en seis sedes a lo largo del país.

La malla curricular actual, vigente desde 2014 y acreditada por el Consejo Nacional de Acreditación de Chile desde 2015, no contiene elementos de contexto referidos estudios de género, ni desde la teoría de la traducción ni desde la práctica traductora; no obstante, la malla incluye aspectos específicos del intercambio entre sociedades, particularmente en el contexto económico y gestión de las relaciones, por su mención en Negocios Internacionales. El perfil señala que el egresado estará en condiciones de "traducir textos del inglés al español que faciliten la comunicación entre culturas, conforme a estándares y normas de la profesión, mediante el uso integrado de herramientas tecnológicas" (Universidad Tecnológica de Chile INACAP, 2018).

En este caso, también se plantea un desafío de planificación curricular, ya que el programa es estandarizado a partir de un descriptor de asignatura que aborda no solamente las evaluaciones, sino que las actividades pedagógicas, dejando poco margen para las modificaciones locales de las asignaturas, "de manera de tratar de estandarizar lo más posible y que sea lo más homogéneo en el resultado del aprendizaje en todas las sedes". Pero como señala Serrano, es algo difícil de monitorear, porque "nosotros no tenemos cómo saber si en definitiva se cumple exactamente con lo que queremos que se cumpla".

Los aspectos modificables del programa tienen que ver entonces con los contenidos que se pueden incorporar, ya sea por interés regional, consideraciones académicas o intereses de los propios alumnos. A nivel general el programa de INACAP, según plantea Serrano, presenta un espíritu flexible a la hora de desarrollar modificaciones de la malla curricular, considerando estudios de empleabilidad, evaluación por parte de los egresados y análisis de expertos desde el punto de vista tanto laboral como académico. Se toman en cuenta las necesidades de los estudiantes, además de las diversas necesidades relacionadas a la localización de las sedes y sus contextos productivos y de mercado, pero con un fuerte enfoque en la estandarización de los contenidos, lo que significa un desafío logístico a la hora de coordinar actividades en todas las sedes.

Asimismo, se realizan actividades de formación general de forma habitual, tales como charlas y talleres que son coordinados por un programa o sede en particular, pero que son abiertas a toda la comunidad educativa. Se- 
gún Serrano, "es voluntario para cada alumno ir o no ir, pero si hay una inquietud por incluir temas de actualidad", lo que abre la posibilidad de considerar los procesos de evaluación constantes del programa de Traducción de INACAP, para incorporar temáticas de estudios de género y Traducción desde esta modalidad extracurricular.

El programa de Magíster en Traducción de la Pontificia Universidad Católica presenta otra arista de la planificación curricular, ya que proviene de la reorganización de la primera carrera de Traducción que se estableció en 1971 y que se reestructuró a fines de la década de 1990. Fue el primer magíster profesional de la Facultad de Letras el 2009, acreditado desde 2017 hasta 2023 (Pontificia Universidad Católica, 2018) y su malla curricular no es de especialización, sino de formación de un traductor generalista con dos áreas de trabajo: Traductología (con asignaturas de teoría de la traducción y metodología de la investigación, entre otras de carácter académico de la disciplina) y Tradumática, además de cinco talleres de traducción a elección de los alumnos, referidos a las áreas de mayor demanda en Chile que se actualizan a partir de los estudios de mercado desarrollados cada dos años por la académica entrevistada (29 de noviembre 2018) de esta universidad, María Isabel Diéguez, profesora asociada y exdirectora del Magíster en Traducción.

Este programa le ha dado una importancia relativa al contexto sociocultural, pues se enfoca en la práctica de la traducción mediante talleres electivos en los que se integran contenidos de política, relaciones internacionales, educación, psicología entre otros. No obstante, es flexible a integrar los intereses de los alumnos y la contingencia por medio de los procesos de revisión de las asignaturas que se realizan de manera anual y cada dos años para la evalua- ción del programa mediante jornadas y procedimientos. Por ejemplo, como señala Diéguez, una vez finalizado el curso "yo le pedía a los profesores que entregaran el programa que realmente le entregó a los estudiantes y luego la planificación sesión a sesión de lo que realmente hizo, porque uno tiene muy buenas intenciones, pero termina haciendo a veces no todo lo que se propuso" (2018). Esto, junto con reuniones constantes del comité académico, establece una base para la generación y revisión de las asignaturas y da cuenta de la adaptabilidad relativa mediante la actualización constante de las actividades, contenidos y asignaturas propuestas para los electivos de la malla curricular, de las asignaturas regulares y del programa en general a partir del control anual.

En cuanto a la inclusión del factor género en esta institución, esta se ha trabajado a partir del desarrollo actividades en paralelo a la malla curricular, tales como tesis de grado, actividades de extensión, coloquios y talleres con profesores extranjeros especialistas. Se menciona, por ejemplo, la visita de la académica canadiense Luise von Flotow en 2001 a la carrera de pregrado. Y, aunque no es prioritario dentro de los contenidos curriculares al ser un programa generalista más que de especialidad, se evidencia el interés en incluirlo en los contenidos curriculares o las líneas de investigación en la próxima revisión de la malla del programa, según indica Diéguez (2018).

Desde el aspecto de las movilizaciones feministas en la educación superior, Diéguez también plantea que, a diferencia del pregrado que cuenta con un centro de alumnos y que plantea instancias para que los estudiantes reflexionen frente a diversos temas, el programa actual no tiene centro de alumnos y funciona en un horario reducido dentro de la universidad, por lo que los estudiantes cuentan con 
pocas opciones de encuentro fuera del horario de clases. Casi toda la relación social de dicha comunidad queda establecida en las horas de estudio en biblioteca y, por tanto, afirma Diéguez, se observa baja movilización social efectiva en este grupo de estudiantes, pues plantea que "las instancias de colaboración son más virtuales" (2018).

En el caso de la Universidad de las Américas, se ha integrado la relación género y Traducción a partir de diversas estrategias, lo que habla del interés de su comunidad por incorporarlo a partir del enfoque de mediación cultural y diversidad que la nueva malla y perfil de egreso le quieren dar a sus egresados. Marion Zepeda, Directora de la Escuela de Traducción e Interpretación en Inglés, en una comunicación oral (16 de noviembre, 2018) explica que el tema se ha tocado de manera indirecta, es decir fuera de la organización formal de la planificación curricular, tanto como contenido de reflexión en las asignaturas, particularmente de mediación e interculturalidad, y mediante actividades extracurriculares, como charlas que abarcan desde prevención de VIH a charlas de Traducción y género ${ }^{2}$, que los propios estudiantes han solicitado por intereses particulares.

Esta nueva planificación pedagógica se encuentra vigente desde el 2018 y refuerza la autoevaluación constante del currículo y el reforzamiento e incorporación de asignaturas con enfoque en la transculturalidad de la disciplina, el rol del traductor en el contexto de las ciencias sociales y las humanidades y desarrollo de pensamiento crítico respecto de la teoría e

2 Fue solicitada por las autoridades de la carrera a la investigadora principal de este estudio, Dra. Rosa Basaure y fue realizada durante noviembre de este año en el campus Providencia de la Universidad de las Américas. (UDLA noticias, 2018). investigación en Traducción. Pero Zepeda, en una comunicación oral junto a Álvaro Salazar, Director de Carrera Traducción e Interpretación en Inglés, Campus Providencia (16 de noviembre, 2018), establecen que no existe la posibilidad de incorporar este factor a un electivo y señalan que en la malla de esta institución no hay electivos, que es "tal vez de los puntos que nosotros, de las falencias que podemos abordar nuevamente para la revisión curricular, tal vez transformar algunos contenidos de asignaturas (o) agregar una nueva asignatura" (2018).

De acuerdo a este análisis, es posible establecer entonces que, si bien los programas muestran asignaturas de enfoque sociocultural, aún no se logra ver explícitamente que las temáticas de género y traducción se incorporen de manera constante y metódica a las mallas curriculares y al perfil de egreso. Sin embargo, en la mayoría de los programas se observa el interés por la materia y la conciencia de que las movilizaciones universitarias del año 2018 presentan un nuevo contexto social que debe tratarse en los programas de Traducción del país y hacer frente al interés de los estudiantes y los cambios en el contexto disciplinar y laboral que deberán enfrentar los futuros egresados.

\section{Una nueva propuesta curricular: electivo de Traducción y Estudios de Género en el programa de Licenciatura en Lingüística Aplicada a la Traducción de la Universidad de Santiago de Chile}

Para incorporar el contexto de diversidad de género a la malla curricular o perfil de egreso, se propone la flexibilización del currículo, con el fin de que sea posible profundizar líneas de investigación y práctica de la traducción a partir del desarrollo de asignaturas electivas que puedan incorporarse a la malla curricular a medida que se generen cambios de intereses 
o de contextos dentro de las propias organizaciones educativas.

Para el caso de estudio entonces, se presenta la asignatura electiva de Traducción y Estudios de Género de la carrera de Lingüística aplicada a la Traducción de la Universidad de Santiago de Chile, que corresponde a la última de las alternativas de flexibilización curricular presentadas en esta investigación.

\subsection{Contexto}

Como se ha señalado, la relación género y traducción ha sido poco explorada, ya que nuestro país ha quedado atrás en el debate al no existir formación específica ni desde la teoría ni desde la práctica en esta materia. En este sentido, el saber traductológico sometido a la transposición didáctica debe considerar ambos aspectos de la disciplina para el logro de un nuevo contrato didáctico, considerando que actualmente las clases se diseñan fundamentalmente buscando cómo transmitir más conocimiento en menos tiempo, es decir están centradas en la actividad explicativa del que enseña (Giordan, 1982).

Es así como se considera la necesidad de que los profesores sean facilitadores, conscientes del contexto e intereses de los estudiantes, inspirándolos y desafiándolos a establecer su propio proceso de aprendizaje. La planificación, ejecución y evaluación se debe realizar a partir de nuevos lineamientos de aprendizaje activo $\mathrm{y}$, en el caso concreto de este trabajo, nuevos lineamientos que permitan el logro de un proceso eficiente, activo y aplicado de la traducción.

Para contextualizar la asignatura de Traducción y estudios de género, se puede señalar que esta se dicta en el octavo semestre de la actual malla curricular de la carrera de Licenciatura en Lingüística aplicada a la Traducción, men- ción inglés y japonés e inglés y portugués que entrega el Departamento de Lingüística y Literatura de la Facultad de Humanidades de la Universidad de Santiago de Chile, que declara noventa horas cronológicas en el semestre. Dentro del plan de estudios, la asignatura se vincula con los ciclos de lenguas y de traducción y tiene como prerrequisito las asignaturas del séptimo nivel de la carrera, pues para cursarla es necesario haber adquirido las competencias para la práctica de la traducción. Se supone en su conducta de entrada diversos conocimientos y habilidades de todos los cursos anteriores de las líneas de lengua inglesa y lengua de mención (japonés o portugués), pero también de la línea de español como lengua materna (gramática del texto, expresión oral y escrita, semántica, entre otros), además del interés particular en la materia. Del plan de estudios, se presenta solo la mención inglés y japonés como una figura referencial.

\subsection{Relación con el perfil de egreso y los objetivos de aprendizaje}

La asignatura electiva establece que, en relación con el perfil de egreso, contribuye al desarrollo de la competencia profesional de "Comprender y transmitir el sentido de un mensaje escrito de una lengua a otra con fidelidad" (Universidad de Santiago de Chile, 2018a).

Como resultado de aprendizaje general, el programa del curso de Traducción y Estudios de Género 2018 establece como objetivo:

conocer la evolución histórica de la relación entre el factor de género y traducción en diferentes contextos socioculturales; las relaciones teórico-prácticas entre género y traducción y los roles y competencias fundamentales de los traductores para la práctica de la disciplina, que les permita tomar decisiones en un contexto de paradigmas cambiantes en lo que respecta a género. (Comunicación interna USACH, 2018) 


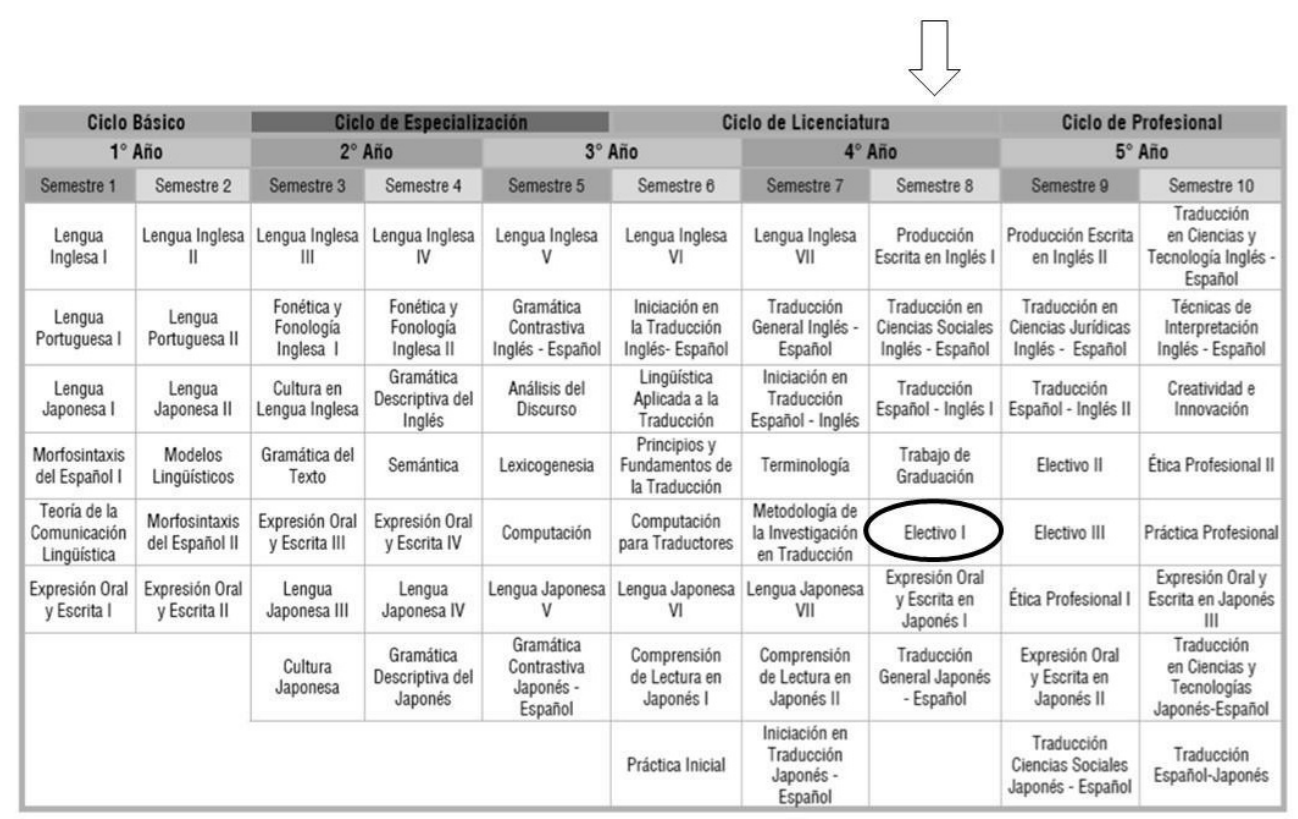

Figura 1. Malla curricular de la carrera de Licenciatura en Lingüística aplicada a la Traducción mención inglés-japonés e inglés-portugués.

Fuente: Universidad de Santiago de Chile (2018).

La asignatura además desarrolla como resultados de aprendizaje específicos: analizar desde la mirada intercultural los estereotipos de género y el desarrollo histórico del feminismo y de los movimientos de diversidad sexual; describir las relaciones entre género y uso del lenguaje, y reflexionar respecto de la relación entre género y traducción. Se evidencia así que la asignatura está directamente relacionada con el desarrollo de un alto nivel de dominio de las lenguas debido a la aplicación de dicho dominio al marco de la reflexión y práctica de la traducción, considerando también conocimientos extralingüísticos y culturales.

Asimismo, el curso contribuye de manera indirecta a la competencia profesional de comunicación establecida en el perfil de egreso de la carrera, que se define como ser capaz de "expresarse con fluidez en forma oral y escrita en las lenguas que utiliza profesionalmente" (Universidad de Santiago de Chile, 2018a).
Esto se refleja en el resultado de aprendizaje general actual del programa de la asignatura y su alineación con la asignatura previa de Principios y fundamentos de la traducción, que plantea que los alumnos aplicarán el conocimiento adquirido respecto de la lenguas al conocimiento de la traducción, considerando dentro de los contenidos el análisis crítico respecto de la evolución de los conceptos de traducción y traductología en diferentes contextos históricos y de acuerdo con distintas corrientes de pensamiento en el mundo; las modalidades de traducción y los roles y competencias fundamentales del traductor, y las teorías contemporáneas, así como técnicas y estrategias para la práctica de la traducción.

Por lo tanto, se puede establecer que la asignatura es pertinente pues se alinea con la malla curricular y el perfil de egreso, en cuanto a que espera que los futuros traductores apliquen a la reflexión respecto de la teoría y la práctica de la traducción las bases teóricas del enfoque 
de traducción y género. Se espera además que analicen los modelos presentados en la teoría de traducción a lo largo de la historia y que incluyen las últimas actualizaciones en la materia, así como también que resuelvan casos prácticos de traducción, para abrir la reflexión a la importancia de este tema dentro de la disciplina.

\subsection{Estructura de la propuesta curricular de la asignatura de Traducción y Estudios de Género}

La propuesta se desarrolla entonces en el marco de una asignatura electiva que promueve la adaptabilidad práctica de los alumnos a las teorías y enfoques de género para la traducción, que responde al aprendizaje autónomo de conocimientos y habilidades para el desempeño de su profesión en esta área y el desarrollo de un conocimiento acabado de las características de esta temática. Lo anterior se refleja en un proceso de aprendizaje centrado en el quehacer del alumno en el que este es el gestor de su propio conocimiento, lo que es congruente con el Modelo Educativo Institucional (MEI) de la Universidad de Santiago de Chile (Universidad de Santiago de Chile, 2018b).

En cuanto a los contenidos, se plantea una estructura que entrega un panorama amplio del debate internacional y una mayor profundidad analítica al proceso de aprendizaje de los alumnos. Se consideran conceptos utilizados en teoría de la traducción a partir de este enfoque, elementos de contexto histórico y la situación actual de la materia, representantes y antecedentes relevantes, las principales corrientes teóricas, así como el análisis de las estrategias y ejemplos que permiten validar este enfoque a partir de la teoría y práctica de la traducción.
La estructura del programa de asignatura incorpora específicamente conceptos y contenidos relativos a estereotipos y movimientos sociales (estereotipos culturales y sociales sobre género, historia de los movimientos feministas y de diversidades); conceptos fundamentales (género, lenguaje no sexista, fidelidad, retraducción, apropiación); teorías de traducción y género (enfoque feminista, enfoque de diversidades, nuevas corrientes); roles y competencias fundamentales para los futuros traductores desde la perspectiva de género; relación género y lenguaje (sexismo lingüístico gramatical y sintáctico, debate sobre el lenguaje no sexista en inglés y en español), y análisis de problemas prácticos de traducción desde el punto de vista de género.

Dentro de las referencias teóricas que se incluyen en la asignatura, se encuentran autores referentes a nivel internacional tales como Olga Castro, Emek Ergun, Amparo Hurtado, Luise von Flotow, Anna Gil Bajardí, Douglas Robinson, Mona Baker, José Santaemilia, Mirko Casagranda, Jeremy Munday y Mary Snell-Hornby, además de páginas web como las de la UNESCO y los Ministerios de Cultura y de la Mujer y la Equidad de Género de Chile, entre otras.

Respecto de las actividades de la asignatura, se plantea un diseño teórico-práctico que se basa en los modelos educativos contemporáneos, particularmente el constructivista, desde el punto de vista de la generación de aprendizaje activo (Coll, 2002). Aquí, no se espera del alumno la memorización de datos y características generales extraídas de fuentes bibliográficas específicas, sino que considere estrategias y técnicas didácticas enfocadas al aprendizaje activo y colaborativo mediante ciclos (Sanmartí, 2002). Además, la evaluación de dichas actividades debe ser el reflejo de un proceso colaborativo de reflexión con apoyo 
de lecturas complementarias, siendo una herramienta de generación de conocimiento reflexivo en la que los alumnos se ven involucrados en su proceso de aprendizaje, en el que el propósito de la evaluación no es demostrar, sino perfeccionar el proceso de aprendizaje (Stufflebearm, DL. y Shinkfield, AJ., 1987).

Por lo anterior, involucrar al estudiante en las actividades plantea el enorme desafío de encantarlo frente a una nueva visión en el quehacer de la disciplina desde el punto de vista teórico. Se establecen así actividades que profesionalizan el proceso de desarrollo en la entrega de aprendizaje a partir de sus fases (Sanmartí, 2002).

\section{SECUENCIACIÓN DE LAS ACTIVIDADES}

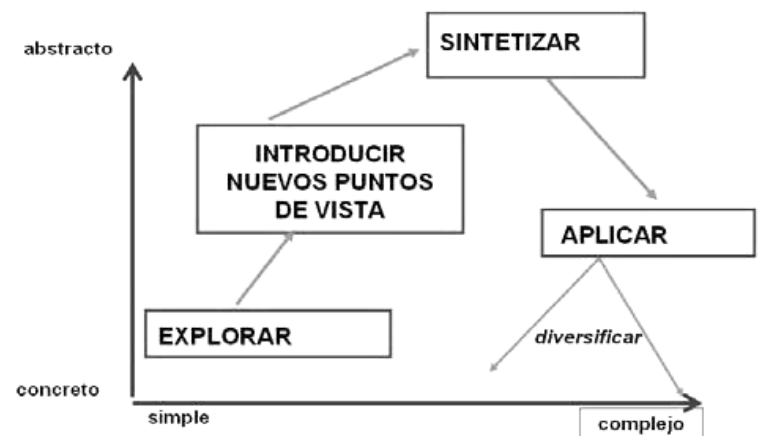

Figura 2. Secuenciación de actividades a partir del modelo educativo constructivista.

Fuente: Sanmartí, 2002.

Asimismo, se propone la realización de actividades orientadas a la construcción o reconstrucción de nuevos aprendizajes o puntos de vista por parte de los alumnos que son guiados por el profesor como facilitador de la asignatura. Se favorece la identificación de nuevas formas de resolver problemas de traducción a partir del enfoque de género, con el objetivo de que el estudiante interprete y modele de forma nueva los fenómenos que se le presentan y que pueda establecer comparaciones entre sus creencias y la reflexión grupal respecto de lo recopilado para identificar comparaciones entre las teorías de la traducción trabajadas. Se espera que las actividades permitan que cada estudiante relacione y sintetice la información, a partir de la reflexión para la construcción de conocimiento mediante las diferentes formas de resolución de los problemas planteados, por lo que se contempla el uso de recursos audiovisuales, talleres de aplicación práctica y presentaciones de los alumnos, además del trabajo personal y autónomo dentro y fuera del aula.

\section{Conclusiones}

Los resultados de esta investigación levantan la necesidad de hacer modificaciones curriculares para enfrentar los desafíos que se plantean para la formación de los futuros traductores desde un contexto sociocultural cambiante, que requiere de un profesional con una visión integral e integradora. En la actualidad, se hace necesario incorporar el enfoque de género en los programas de Traducción en América Latina y en Chile, en particular, considerando la situación de esta materia a nivel internacional, las movilizaciones feministas del año 2018 y la experiencia concreta de la Universidad de Santiago de Chile respecto de la incorporación del debate de género a la malla curricular de la carrera de Licenciatura en Lingüística Aplicada a la Traducción como asignatura electiva.

En este sentido, se puede concluir que como plantea Castro, "estamos asistiendo a un proceso en el que cada vez más los feminismos exigen su sitio en los Estudios de Traducción, de igual modo que la traducción lucha por su propia parcela en los Estudios de Género" (Castro, 2008, p. 285). Resulta necesario entonces establecer mecanismos que permitan actualizar contenidos, estrategias pedagógicas y programas de asignaturas, considerando la posibilidad de un currículo flexible en estas 
materias, dada la relevancia de la competencia extralingüística en las mallas curriculares de traducción, tanto para Chile como a nivel latinoamericano considerando el contexto de un mundo globalizado.

Independiente de la estrategia de incorporación al currículo, la importancia de incluir el contexto social para la formación de traductores, y el factor de género en particular, es fundamental para el desarrollo de los futuros profesionales de la traducción, por lo que las instituciones de educación superior que tienen la responsabilidad de formar a los futuros traductores deben dar cuenta del contexto global cambiante que determinará en el futuro el estudio, la práctica y la investigación en la disciplina. El cambio hacia una visión más amplia de la diversidad del debate teórico y la apreciación de los nuevos enfoques de la disciplina, así como la aplicación de aquellos a la experiencia práctica, permitirá a los traductores contar con criterios de análisis para las representaciones de género, que adquieren una categoría de nivel especial. Los traductores tendrán la responsabilidad no solo del traspaso de lo cultural, sino que del tratamiento del discurso desde las diversidades más allá de transmitir códigos de un contexto regional particular, representan las voces y los conflictos de un entorno global. La incorporación de una asignatura relacionada con la temática de género contribuye a fortalecer la formación de los traductores pues produce la apertura de la mentalidad traductora para desarrollar su potencial creativo, a través de diferentes formas de abordar la traducción.

En particular, mediante la implementación de la asignatura de Traducción y Estudios de Género en la formación de los traductores de la Universidad de Santiago de Chile, se espera dar una alternativa pedagógica para que los estudiantes alcancen el logro del aprendizaje profundo mediante la búsqueda activa de información. Esta alternativa promueve el hecho de que los estudiantes no son observadores y que el profesor como facilitador les entrega responsabilidad desde su proceso personal y colectivo. Se incentiva tanto el trabajo individual como el colaborativo para incorporar el conocimiento desde el desarrollo de las distintas tareas de la asignatura basadas en reflexión crítica, estudio de casos y aprendizaje por proyecto.

Asimismo, pese a la necesidad de revisar la situación de toda América Latina en este contexto, esta investigación es un avance en la materia, ya que permite contar con un corpus inicial para establecer un marco preliminar y actualizado de la situación de los programas de traducción desde este enfoque geográfico particular. Así, este estudio abre el camino no solo para la flexibilización del currículo académico en este campo, sino que a su vez constituye una oportunidad para el desarrollo de nuevas líneas de formación, práctica e investigación de la traducción desde la visión de América Latina, a partir de la experiencia del caso chileno.

Finalmente, cabe observar que el traductor en formación no puede estar alejado del contexto en el desarrollo de la competencia traductora, pues conocerlo le permite generar conciencia sobre las identidades sociales y culturales que lo rodean. Los futuros profesionales de la traducción constituyen el capital humano avanzado que trabajará directamente con otras culturas y, por tanto, serán agentes claves en el desarrollo integral de las relaciones internacionales.

\section{Referencias}

Anderson, B. (1993). Comunidades imaginadas. Reflexiones sobre el origen y la difusión del 
nacionalismo. México: Fondo de Cultura Económica.

Bachman, L. (1995). Habilidad lingüística comunicativa. En M. Llobera (Coord.), Competencia comunicativa. Documentos básicos en la enseñanza de lenguas extranjeras. Madrid: Edelsa.

Bhabha, H. (2002). El lugar de la cultura. Buenos Aires: Manantial.

Butler, J. (1990). Gender trouble. Feminism and the subversion of identity. New York: Routledge.

Canale, M. (1995). De la competencia comunicativa a la pedagogía comunicativa del lenguaje. En M. Llobera Cànabes (Coord.), Competencia comunicativa. Documentos básicos en la enseñanza de lenguas extranjeras. Madrid: Edelsa.

Cantor, N. (1973). La era de la protesta. Madrid: Alianza.

Castro, O. (2008). Género y traducción: elementos discursivos para una reescritura feminista. Lectora, 14, 285-301. Recuperado de http://revistes.ub.edu/index.php/ lectora/article/view/7155/9059

Castro, O. (2013). Introduction: Gender, language and translation at the crossroads of disciplines. $G \& L, 7(1), 5-12$, Equinoxpublishing. https://doi.org/10.1558/genl.v7i1.5

Cohen, J. (1985). Strategy or identity: New theoretical paradigms and contemporary social movements. Social Research: An International Quarterly, 53(1), 663-716.

Coll, C. (2002). Constructivismo y educación: la concepción constructivista de la enseñanza y el aprendizaje. En C. Coll, J. Palacios y A. Marchessi, Desarrollo psicológico y educación (tomo II). Madrid: Alianza.

Consejo Nacional de Educación Superior de Chile (2018). Respecto del cierre del Instituto Chileno Norteamericano. Recuperado de http://www.cned.cl/institucion/instituto-profesional-chileno-norteamericano

Consejo Nacional de Educación Superior de Chile (2018). Respecto del cierre de la Uni- versidad Chileno Británica. Recuperado de http://www.cned.cl/institucion/universidad-chileno-britanica-de-cultura

Cooperativa.cl (2018, 29 de mayo). Más de 30 universidades ya están movilizadas por demandas feministas. Radio Cooperativa digital [archivo de audio]. Recuperado de https://www.cooperativa.cl/ noticias/pais/educacion/movimiento-estudiantil/mas-de-30-universidades-ya-estan-movilizadas-por-demandas-feministas/2018-05-29/123325.html

De la Maza, G. (2005). Tan lejos tan cerca. Politicas públicas y sociedad civil en Chile. Santiago de Chile: Lom.

De Ramón, A. (2003). Historia de Chile: desde la invasión incaica hasta nuestros días. 15002000. Santiago de Chile: Catalonia.

Diéguez, M. I.; Lazo, R. y Quezada, C. (2014). Estudio de mercado de la traducción en Argentina, Chile y España: perfil académico y profesional de los traductores. Onomázein, Revista semestral de lingüistica, filología y traducción, 30, 70-89. Recuperado de http://onomazein.letras. uc.cl/Articulos/N30/30_6_Dieguez_FINAL.pdf https://doi.org/10.7764/onomazein.30.6

Eckert, P. y McConnell-Ginet, S. (2002). Language and gender. Cambridge: Cambridge University Press.

Ehrlich, S. (1997). Gender as social practice: implications for second language acquisition. Studies in Second Language Acquisition, 18, 421-446. https://doi.org/10.1017/ S0272263197004014

Eldinamo.cl. (2018, 23 de mayo). Movimiento feminista ya concentra 17 paros y 22 tomas en distintas universidades. El Dínamo, diario digital. Recuperado de https://www. eldinamo.cl/educacion/2018/05/23/ movimiento-feminista-ya-concentra-17-paros-y-22-tomas-en-distintas-universidades/ 
Federici, E. (Ed.) ( 2011). Translating gender. Berna: Peter Lang AG. https://doi. org/10.3726/978-3-0351-0198-0

Feminismo (2017). En Diccionario de la lengua española. Recuperado de http://dle.rae. es/?id=HjuyHQ5

Gaspar, M. (2017). Apuntes para una teoría de la traducción latinoamericana. Literatura: Teoría, Historia, Crítica, 19(2), 231246. https://dx.doi.org/10.15446/lthc. v19n2.63183

Gaviola, E., Jiles, X., Lopresti, L., y Rojas, C. (1986). Queremos votar en las próximas elecciones. Historia del movimiento femenino chileno 1913-1952. Santiago de Chile: Coedición Centro de análisis y difusión de la condición de la mujer/ La Morada, Fempress/Ilet, Isis, Librería Lila, Pemci/Centro de Estudios de la Mujer.

Giordan A. (1982). La enseñanza de las ciencias. Madrid: Siglo XXI.

Gobierno de Chile (2013). Mensaje de s. E. el presidente de la República con el que inicia un proyecto de reforma constitucional que establece la obligatoriedad del segundo nivel de transición y crea un sistema de financiamiento gratuito desde el nivel medio mayor $N^{\circ} 091$ 361. Recuperado de http://bit.do/ePvBo

Grimson, A. (2000). Interculturalidad y comunicación. Buenos Aires: Norma.

Guerra, J. (2018, 18 de junio). Feministas entregaron petitorio a rector de la Universidad de Chile [podcast en audio]. ADN Radio digital. Recuperado de http://www.adnradio. cl/noticias/nacional/feministas-entregaron-petitorio-a-rector-de-la-universidad-de-chile/20180618/nota/3763685. aspx

Hurtado, A. (2001). Traducción y traductología: introducción a la traductología. Madrid: Cátedra.

Instituto Profesional EATRI (2018). Quiénes somos. Instituto Profesional EATRI. Recuperado de http://www.eatri.cl/quienes-somos/
Kelly, D. (2002). Un modelo de competencia traductora: bases para el diseño curricular. Puentes. Hacia nuevas investigaciones en la mediación intercultural, (1), 9-20. Recuperado de http://wpd.ugr.es/ greti/revista-puentes/pub1/02-Kelly.pdf

Kiraly, D. (2000). A social constructivist approach to translator education. Empowerment from theory to practice. Manchester: St. Jerome Publishing

Ley 19947: Establece nueva ley matrimonio civil, 2007. Recuperado de https://www. leychile.cl/Navegar?idNorma $=225128$

Márquez, D. (2011). Las once competencias del traductor: el perfil ideal en servicios de traducción. Comunicación, Cultura y Politica. Revista de Ciencias Sociales, 4, 53-68.

Melucci, A. (1989). Nomads of the present: Social movements and individual needs in contemporary society. Pennsylvania: Temple University Press.

Ministerio de la Mujer y la Equidad de Género (2018). Sobre el ministerio. Recuperado desde https://www.minmujeryeg.cl/ministerio/

Montes, R. (2018, 16 de mayo). La nueva ola feminista chilena explota en las universidades. El País. Recuperado de https:// elpais.com/internacional/2018/05/16/ america/1526477379_243906.html

Morgan, R. (Coord.). (1993). Mujeres del mundo. Atlas de la situación femenina. 80 países vistos por sus mujeres. Vindicación Feminista. Madrid: Hacer.

Observatorio de Género y Equidad (2013). Resistencia y lucha de mujeres en dictadura. Recuperado de http://oge.cl/mujeres-en-resistencia/\#

PACTE (2001). La competencia traductora y su adquisición. Quaderns. Revista de Traducció, 6, 39-45. Recuperado de http://www3. uji.es/ aferna/H44/Translation-competence.pdf 
PACTE (2018). Competence levels in translation: working towards a European framework. The Interpreter and Translator Trainer, 12(2), 111-131. Recuperado de https:// ddd.uab.cat/record/194868

Paz, O. (1971). Traducción, literatura y literalidad. Barcelona: Tusquets.

Penas, M. (2015). (Ed.) La traducción. Nuevos planteamientos teórico-metodológicos.Madrid: Síntesis.

Pontificia Universidad Católica de Chile (2018). Programa de Traducción de la Pontificia Universidad Católica de Chile. Recuperado de http://programas.letras. uc.cl/index.php/descripcion/20-programa-de-traducción

Pontificia Universidad Católica de Chile (2018). Magíster en Traducción, inglés al español Recuperado de http://posgrado. letras.uc.cl/index.php/magister/magister-traduccion-ingles-al-espanol

Pontificia Universidad Católica de Valparaíso (2018). Pregrado. Traducción Inglés Español. Recuperado de http://www.pucv.cl/ pucv/pregrado/traduccion-ingles-espanol/2015-06-11/165754.html

Pym, A. (1998). Method in translation history. Manchester: Saint Jerome Publishing.

Sanmartí, N. (2002). Organización y secuenciación de las actividades de enseñanza/ Didáctica de las ciencias en la educación secundaria obligatoria. Madrid: Síntesis Educación

Santaemilia, J. (Ed.) (2005). Gender, sex and translation: The manipulation of identities. Manchester: St. Jerome

Sepúlveda, P. (2018, 20 de mayo). Feminismo chileno vive su revolución más importante en 40 años. La Tercera. Recuperado de https://www.latercera.com/tendencias/ noticia/feminismo-chileno-vive-revolucion-mas-importante-40-anos/172111/

Simon, S. (1996), Gender in translation. Cultural identity and the politics of transmission. London: Routledge.
Stufflebearm, D. L. y Shinkfield, A. J., (1987). Evaluación sistemática. Guía teórica y práctica. Barcelona: Paidós-MEC.

Universidad Arturo Prat (2018). Admisión 2019. Recuperado de http://www.unap. cl/admision/2019/traduccion.html

Universidad Católica del Norte (2017). Diplomado. Recuperado de https://www.youtube.com/watch?v=OQ1LGdbl-ck\&feature $=$ youtu.be

Universidad Católica de Temuco (2018). Admisión. Traducción. Recuperado de https://admision.uct.cl/traduccion/

Universidad Chileno Británica (2018). Carreras: Traducción Inglés Español. Recuperado de http://www.ubritanica.cl/carreras/ traduccion-ingles-espanol

Universidad de Atacama (2018a). Mallas Facultad de Humanidades. Malla Traducción Inglés Español. Recuperado de http://www. uda.cl/images/pdf/mallas-fac-humanidades/malla-trad-ingles-espanol.pdf

Universidad de Atacama (2018b). Perfil de egreso. Recuperado de http://bit.do/ePvB4

Universidad de La Serena (2018). Traducción Inglés-Español. Recuperado de http:// www.userena.cl/boton-carreras/item/ traduccion-ingles-espanol.html

Universidad de las Américas (2018a). Admisión. Carrera de Traductor e Intérprete en Inglés. Recuperado de https://admision. udla.cl/carrera/traduccion-e-interprete-en-ingles

Universidad de las Américas (2018b). Noticias: Escuela de Traducción realiza charla sobre traducción y género en Campus Providencia. Recuperado de http://noticias.udla.cl/ escuela-de-traduccion-realiza-charla-sobre-traduccion-y-genero-en-campus-providencia/

Universidad de Playa Ancha (2018). Traducción e Interpretación Inglés-Español. Recuperado de http://www.upla.cl/admision/ carreras-profesionales/facultad-de-huma- 
nidades/traduccion-e-interpretacion-ingles-espanol/

Universidad de Tarapacá (2018). Admisión. Licenciatura en Inglés. Recuperado de http:// admision.uta.cl/licenciatura-en-ingles/ admision/2016-03-11/163214.html

Universidad de Santiago de Chile (2018a). $\mathrm{Li}$ cenciado en Lingüistica aplicada a la traducción mención en inglés-japonés o inglés-portugués. Recuperado de https://www. fahu.usach.cl/licenciatura-en-linguistica-aplicada-la-traduccion-en-ingles-japones-e-ingles-portugues

Universidad de Santiago de Chile (2018b). Modelo educativo institucional. Versión actualizada 2013. Recuperado de https://www. usach.cl/sites/default/files/documentos/files/mei_2014.pdf

Universidad Tecnológica de Chile INACAP (2018). Traductor Inglés-Español, Mención Negocios Internacionales Recuperado desde http://www.inacap.cl/tportalvp/humanidades-y-educacion/contenido/carreras/traductor-ingles-espanol-mencion-negocios-internacionales

Universidad UNIACC (2018). Traducción e interpretariado bilingüe (inglés-español). Recuperado de http://www.uniacc.cl/ carrera/traduccion-e-interpretado-bilingue-ingles-espanol/\#malla

Venuti, L. (2004). The translator's invisibility: A history of translation (Reimpresión digital). UK: Taylor \& Francis e-Library. Recuperado de http://bit.do/ePvCT

Vera, J. (2017). Las heridas de Nabila Rifo. La historia del femicidio frustrado más infame de Chil [Memoria para optar al título de periodista, categoría reportaje]. Universidad de Chile, Instituto de la Comunicación e Imagen Escuela de Periodismo, Santiago, Chile). Recuperado de http://repositorio.uchile. cl/bitstream/handle/2250/150567/Tesis-Las-heridas-de-Nabila-Rifo.pdf?sequen$\mathrm{ce}=1 \&$ isAllowed $=\mathrm{y}$

Von Flotow, L. (1997). Translation and gender: Translating in the 'era of feminism'. Manchester: St Jerome Publishing.

Von Flotow, L. (2006). Feminism in translation: The Canadian factor. Manchester: St Jerome Publishing.

Von Flotow, L. (Ed.) (2011). Translating women. Ottawa: University of Ottawa Press.

Wallerstein, I. (2007). Geopolitica y geocultura. Ensayos sobre el moderno sistema mundial. Barcelona: Kairós.

Wittgenstein, L. (2012 [1921]). Tractatus logico-philosophicus. España: Alianza.

Cómo citar este artículo: Basaure-Cabero, R. I. y Contreras-Torregrosa, M. (2019). Movimientos feministas y enfoques de género: integración del debate en las líneas curriculares para la formación de traductores en Chile. Mutatis Mutandis, 12(1), 156-181. Dor: 10.17533/udea.mut.v12n1a06 